\title{
PRE-SEMIOTICIDADES. APUNTES SOBRE UNA FRONTERA ENTRE MEMORIA PREHISTÓRICA Y LENGUAJES DEL ARTE
}

\author{
PRE-SEMIOTICITIES. NOTES ON A FRONTIER BETWEEN \\ PREHISTORIC MEMORY AND LENGUAGES OF ART
}

\author{
Ariel GÓMEZ PONCE \\ CONICET, Facultad de Lenguas \\ Universidad Nacional de Córdoba (Argentina) \\ ariel.gomezponce@fl.unc.edu.ar
}

Resumen: Este trabajo busca operativizar categorías de la semiótica de Iuri Lotman con el objeto ampliar el paradigma de sus reflexiones. A partir de la configuración semiótica denominada "cuadro de mundo", analizaremos una secuencia de textualidades recientes que reviven, en sede ficcional, especies extintas, mostrando un desplazamiento que rellena vacíos semánticos con nuevas inscripciones significantes. A través de filmes y modelizaciones digitales de las redes sociales, nuestra hipótesis sostiene que la reactivación semiótica del dinosaurio modela un estado presemiótico: semiotización que interpela el lugar de lo humano en el mundo natural desde sus orígenes evolutivos, cuestionando una mirada antropocéntrica.

Palabras clave: Iuri Lotman. Semiótica cultural. Estados presemióticos. Cuadros de mundo.

Abstract: This paper tries to operationalize categories of Juri Lotman's semiotics in order to expand the paradigm of their reflections. Based 
on a semiotics settings understood as a "picture of the world", we will discuss a sequence of recent textualities which, in fictional key, revive extinct species, relocating in new significant inscriptions. Through films and digital modeling of social networks, our hypothesis argues that this semiotics revival of dinosaur models a a presemiotic state: semiotization which questions the place of the human in the natural world from its evolutionary origins, questioning an anthropocentric vision.

Key Words: Juri Lotman. Cultural semiotics. Presemiotic states. Picture of the world.

\section{INTRODUCCIÓN}

Ante el interrogante de cómo los textos son capaces de actualizar cierto caudal de información pretérita, el semiólogo Iuri Lotman [1923-1993] supuso que era preciso repensar metodológicamente el "evolucionismo trivial, según el cual el pasado de la cultura se asemeja a dinosaurios fósiles" (1998 [1986]: 154). La analogía no es casual, dado que, a los ojos de los sistemas culturales, la metáfora del fósil (pese a orientarse hacia otro sentido heurístico) resulta pertinente para reflexionar sobre el ejercicio del mecanismo de la memoria y la resistencia semántica que ejercen ciertos focos textuales a lo largo de la historia. A través de un texto, indicará Lotman, es posible reconstruir toda una parcela completa de la cultura (recordemos el descubrimiento de las tablillas hititas a finales de 1800 que permitieron comprender todo un colectivo lingüístico y social), de la misma manera que, desde un fragmento óseo petrificado en el tiempo, los paleontólogos pueden revivir un organismo y todo un ecosistema con sus diversos grados de complejidad. En términos semióticos, así como el ser vivo guarda en su estructura genética la historia de su linaje (Barbieri, 2008), todo texto comporta también una memoria que es siempre creativa y, en este caso, no hereditaria (Lotman, 1990).

Pero, ¿cómo trabajan los textos de la cultura aquellos fenómenos de los cuales nuestra humanidad no fue testigo? Como hemos indicado en investigaciones anteriores (Gómez Ponce, 2015), aun de los sucesos más pretéritos, las formas primitivas del arte son centinelas de nuestra primera experiencia como sujetos en el mundo, tal como lo demuestran 
las pinturas rupestres que representan colectivos atávicos del hombre y el primer encuentro con las especies animales. No obstante, sabemos que la historia de los humanos comenzó hace casi 200 mil años: antes del surgimiento del Homo sapiens y aun de las primeras proto-herramientas que dan cuenta de una incipiente cultura, el registro del paso del tiempo es tan solo fósil o geológico y, por ende, biológico. Sin embargo, observamos que, más allá de los conocimientos que ciencias como la antropología y la paleontología buscan impartir, el arte, por su parte, se esmera reiteradamente por recrear este espacio temporal atávico y prehistórico. En esta lógica, un caso recurrente lo ofrecen los dinosaurios, especies a las cuales solo conocemos mediante restos fósiles (fragmentos de huesos, marcas de dentición, coprolitos -excrementos fosilizados-) y por el estudio comparativo con especies contemporáneas, fundamentalmente de sus hermanos filogenéticos más cercanos: los reptiles ${ }^{1}$.

Sabemos que, en el imaginario cultural, la figura del dinosaurio se presenta como recurrente y asidua en diversos órdenes textuales. Desde tratados científicos que buscan comprender la complejidad que comportaban estas misteriosas especies hasta filmes clásicos o dibujos animados, los dinosaurios rememoran un pasado inconmensurable y enigmático que muestra las fisuras de una razón que no termina de comprender cómo seres de significante poder pudieron desaparecer casi por completo de la faz de la Tierra. En otras palabras, la cultura opera mediante la reconstrucción (siempre creativa) de aquello que Iuri Lotman ha llamado un cuadro de mundo, entendido como la configuración de un modelo semiótico de alta complejidad que se determina a partir de la oposición del sistema cultural con espacios externos o pretéritos.

Para dar cuenta de cómo se organiza un cuadro de mundo a partir de una especie que nunca convivió con el humano, nuestra hipótesis de trabajo afirma que el esfuerzo mnémico de la cultura pone de manifiesto una constante creativa que busca revivir, a través de variadas producciones de sentido que se organizan a la manera de un cuadro, la historia misma del

1. Debemos destacar que las aves, por la permanencia de ciertos rasgos que en el curso de la evolución se han mantenido, también pertenecen al clado Sauropsida. Sin embargo, en este trabajo, seguimos la postura de Teresa M. Sánchez (2009), quien admite que, dada la evidencia paleontológica, las aves siguieron un curso evolutivo diferente que derivó en el surgimiento de otros aspectos morfológicos (como, por ejemplo, las plumas), siendo por ello los reptiles actuales, los referentes etológicos, genéticos y aspectuales más cercanos. Por esta razón, por las similitudes y los grandes vacíos que la ciencia aún no puede completar, el conjunto total puede ser inscripto bajo la nómina del reptil. 
planeta y, principalmente, el lugar de lo humano. El objetivo general del presente trabajo consiste en operativizar categorías teóricas de la semiótica cultural de Iuri Lotman que, aunque abordadas en variadas ocasiones y en diversas publicaciones, no han sido profundizadas por el autor. Siguiendo esta propuesta teórica, creemos que resulta de interés ampliar el paradigma de las reflexiones de Lotman y detenernos en los mecanismos semióticos que permiten el diálogo entre el ser humano y el mundo natural, aun aquel prehistórico. Si bien este no fue un tópico central en el edificio teórico lotmaniano y aunque el aspecto jurásico no haya sido de interés para el semiólogo cultural, podemos rastrear ciertas preocupaciones en lugares marginales de sus artículos, sus clases y sus entrevistas que nos permiten reflexionar sobre el modo en que los textos (principalmente, aquellos del arte) permiten el diálogo activo con "estados profundos, a veces muy arcaicos" (1996[1996]: 233).

De manera específica, nos proponemos describir el modo en que, a partir de uno de los mecanismos que le permite a la cultura escenificar determinadas modelizaciones, se configura un abismo semiótico entre la contemporaneidad y el mundo prehistórico. En vistas de alcanzar este objetivo, analizaremos una secuencia de textualidades recientes que reviven, en sede ficcional, especies extintas como los dinosaurios, reubicando estos seres en un desplazamiento que rellena vacíos semánticos con nuevas inscripciones significantes, a partir de una de sus manifestaciones más recurrentes: el Tiranosaurio Rex. A través de filmes recientes como Jurassic World (2015) o The Good Dinosaur (2015) y modelizaciones digitales como aquellas que proponen los memes de las redes sociales, la reactivación semiótica del dinosaurio organiza una topografía que interpela el lugar de lo humano en el mundo natural. Dicho de otro modo, nuestra interacción con otras especies (los modos de competitividad o cooperación), la mirada antropocéntrica y el cuestionamiento de la evolución en la naturaleza son motivos que, interrogados desde una especie que jamás convivió con el ser humano, se reflexionan críticamente desde la construcción de un "cero semiótico" o un estado presemiótico.

\section{LA SEMIÓTICA DE IURI LOTMAN: ACERCA DEL CUADRO DE MUNDO}

En primer lugar, destacamos que, a nivel metodológico, el pensamiento 
de Iuri Lotman, semiólogo ruso radicado en Estonia, ha abordado un amplio caudal de objetos de estudio (literatura, mitología, cine, teatro e historia) hasta llegar a las discusiones que, en el final de su recorrido, abren el campo de una culturología hacia fenómenos más complejos como lo son los mecanismos de lo impredecible, la asimetría cerebral, la personalidad histórica y, lo que más nos interesa en esta investigación, el comportamiento y la conducta tanto individual como masiva. En términos de una semiótica de la cultura, es plausible estudiar estos fenómenos, interrogándonos de qué manera un texto provee una determinada información a partir de la cual podemos reconstruir una porción o una cultura entera (Barei y Arán, 2002). Categoría central junto con las nociones de cultura y modelo, el texto permite pensar cómo funciona todo un sistema cultural, diacrónica y sincrónicamente. Con la propuesta lotmaniana, nos hallamos ante un programa de investigación semiótica interdisciplinar que se inscribe dentro del marco de un pensamiento complejo. Mediante un esfuerzo teórico por vincular arte y ciencia de forma transversal, Lotman entenderá que tanto los modelos científicos como los artísticos producen información, incrementan el conocimiento del mundo y construyen un modelo de la realidad que puede rastrearse genealógicamente en todo sistema cultural.

Ahora bien, para comprender cómo funciona esta perspectiva teórica, resulta de importancia remitirnos al modo en que la cultura organiza la información tanto de su propio sistema como del exterior: en otras palabras, nos referimos a los lenguajes que implementa. Anclado en un pensamiento topológico, Lotman ha entendido que la cultura se presenta como un sistema complejo de textos, definido como una esfera semiótica o, en otras palabras, una semiosfera: un gran mecanismo semiótico cuya particularidad es que los textos se configuran a través de constantes interrelaciones $\mathrm{y}$, fuera de este, existe una imposibilidad de sentido (Lotman, 1990). Para el semiólogo, los textos no pueden (en principio) tener relación con sentidos extraños (no-textos) a menos que puedan ser traducidos/convertidos a alguno de los lenguajes del espacio interno: toda información externa debe ser semiotizada por un determinado espacio cultural. En otras palabras, los lenguajes (lenguas naturales, artificiales, artísticas) son empleados para dar cuenta de la realidad y comportan los mecanismos de codificación semiótica que siempre se encuentran circunscriptos a determinadas coordenadas socioculturales, configurando aquello que Lotman entiende como un "cuadro de mundo" (1998 [1993]: 
147) y que en el Grupo de Estudios de Retórica hemos denominado un "orden de la cultura" (Barei et al., 2006).

A través de este funcionamiento, los sistemas culturales realizan procesos de traducción constante mediante los cuales se "comparan" y establecen analogías entre lo natural y otros sistemas culturales. Desde este parámetro, objetos como animales, plantas, minerales y espacios naturales se cargan de inteligibilidad semiótica que, tanto positiva como negativamente, pone de manifiesto sentidos codificados culturalmente en una misma configuración. Lotman ha referido que, por ejemplo, en el pensamiento mítico, del otro lado de la frontera, se organiza una construcción cultural como es el "mundo de los animales" a través de un sistema de divinidades, seres y sujetos no antropomorfos e inconcebibles que se asocian a grupos hostiles y que, desde el punto de vista social, son excluidos (como, por ejemplo, ha sucedido con estereotipos como el salvaje o el bárbaro).

En esta lógica, Lotman afirmará que el carácter delimitado de todo sistema cultural habilita semióticamente la construcción de dos cuadros principales que se definen como ajenos pero que, al mismo tiempo, determinan toda una gama de semiotizaciones que varían ideológicamente a lo largo de la historia. Aunque estas distinciones y clasificaciones son abstractas dado su carácter teórico, el semiólogo explica que, considerando su posición contraria a la esfera cultural,

si se logra describir una colectividad en la que los distintos textos, representaciones y tipos de conducta dentro de los límites de cada nivel no se liguen en un único cuadro del mundo, entonces se debe hablar de estado precultural $o$ extracultural de la misma (1998 [1969]: 98, la redonda es nuestra).

De esta manera, por un lado, la contraposición con lo natural establece que, sobre el fondo de la no-cultura, el único sistema de signos posible es aquello que Lotman entiende como uno los "rasgos distintivos de la cultura". De allí que defina al mundo natural como el principal cuadro extrasistémico, en tanto "la peculiaridad del hombre como ser cultural necesita de su contraposición con el mundo de la naturaleza" (1999: 44).

Por otra parte, nos encontramos con el segundo cuadro de mundo 
que será el objeto de atención en este trabajo y que Lotman (2000[1992]) entiende como otro de los "supuestos" básicos de la semiótica: la existencia de un espacio pre-semiótico habitado por especies primitivas como, por ejemplo, aquellas concebidas como "pre-hombres". Nos referimos a un metalenguaje que implica una particular comprensión del pasado evolutivo de todas las especies y, en particular, del ser humano. Los aportes de la zoosemiótica (Sebeok, 2001) le permitirán a Lotman afirmar que subyace un error al suponer que hay un estado de "cero cultural" (un "cero semiótico", dirá), que "coincide con el mundo animal" y a partir del cual surge la cultura (2000 [1992]: 194). Fuertemente influenciadas por la antropología y la paleontología del siglo pasado, estas ideas generan todo un complejo semántico de una "mitología del principio" que, según Lotman, explica el proceso de organización social del ser humano a partir de un punto cero incognoscible, antes del cual a los sistemas culturales les resulta posible solamente barajar hipótesis.

En este sentido, los mitos, las leyendas y las formas de la ficción vienen a ocupar un lugar privilegiado como mecanismo para la explicación de un cuadro de mundo antes del devenir humano. Tal es el caso de la prehistoria de nuestra especie que, ante los ojos de la cultura, se presenta como caótica y habitada por seres incoherentes: una imagen estereotipada, por ejemplo, en la figura cultural del cavernícola que ha sido asiduamente replicada en diversas textualidades. Aquí, la frontera se determina no solo como espacio "entre" sino, para ser más específicos, como "tiempo entre".

Lo interesante en este punto es que, en estos estadios tempranos del sistema cultural, las especies animales poseen un papel fundamental ya que estas aún no eran separadas con precisión del colectivo humano: es un "paradigma inevitable" que sirvió de modelo a nuestra especie en un paseo diacrónico que se remonta a un periodo arcaico y que explica, con diversos matices de sentido, qué nos hace humanos. Mitólogos como Vladimir Toporov (con quien Lotman ha trabajado reiteradamente) han definido este aspecto como el "código zoomorfo", mecanismo de semiotización que da cuenta de una modelización de la realidad que le permitió a la cultura volver inteligibles fenómenos no asequibles para la conciencia temprana (como es nuestra propia existencia en el mundo) y que, por ende, articulan cultura/naturaleza cuando aun ambos sistemas se encontraban en vías de una diferenciación cognitiva. Como hemos podido observar en investigaciones anteriores (Gómez Ponce, 2016), esta perspectiva abre interrogantes que 
remiten a nuestro aprendizaje del mundo animal, que va desde los modos de organización social hasta estrategias de alimentación como la caza o la comprensión contemporánea de ciertos sujetos en clave animalizada. El arte aquí es entonces un mecanismo central para (re)pensar los orígenes de la cultura y el pasado.

\section{EL DINOSAURIO COMO TRADUCCIÓN CREATIVA}

Siguiendo esta propuesta teórica, resulta lógico pensar que, en estas construcciones de cuadros de mundo prehistóricos, especies animales que convivieron con las colectividades primitivas humanas hayan influenciado ciertas configuraciones textuales históricas. Son claros ejemplos nuestros primeros depredadores, la megafauna que fue presa de nuestra humanidad y las especies cánidas que comenzaron a convivir con el ser humano. Pero, ¿qué sucede con especies como el orden dinosauria que, desaparecidas más de 200 millones de años antes del surgimiento de los primates, jamás pudieron "dialogar" con el ser humano? ¿Cómo la cultura, a lo largo de los siglos, ha procesado esta interacción que solo se determina por la existencia de vestigios óseos? En este sentido, si el orden mitológico asienta una base como principio explicativo desde lo animal que se mueve sincrónica y diacrónicamente por los sistemas culturales, serán las ciencias (principalmente, la paleontología) quienes han otorgado otro cariz a la cuestión, fundamentando recorridos que intentan explicarnos esta existencia presemiótica desde parámetros más "verosímiles".

Como hemos mencionado líneas arriba, Lotman intuye que un camino hacia el entendimiento de estas actividades intelectuales es a partir de una modelización comparativa entre ciencias duras y ciencias blandas: en otras palabras, de los mecanismos de traducción que, en la frontera de los campos, permiten el tránsito de sentidos entre esferas (que parecen) distantes como son aquella de la ciencia natural y la del arte.

De esta manera, desde un punto de vista modelizante, podemos recordar que la paleontología nos ha indicado que los dinosaurios aparecieron en el mundo hace aproximadamente 230 millones de años, dominando aquel periodo que las ciencias naturales dominan Jurásico (Curtis et al., 2008). Las hipótesis más actuales sostienen que la caída de un asteroide modificó el curso de la vida biológica en la Tierra en el transcurso de casi un año y eliminó a la numerosa variedad de reptiles 
que integraban este orden. Aunque la aniquilación de las especies no fue instantánea, la vida comenzó un proceso de desaparición paulatina por el aumento de temperaturas, los incendios descomunales, las inundaciones, las lluvias ácidas, los numerosos terremotos, la falta de recursos y la competencia extrema, afectando principalmente a todo el territorio de América (Sánchez, 2009). Para las especies saurias de gran tamaño que dependían más de la visión que del olfato (sentido poco desarrollado en estos organismos), este impacto ambiental y la ausencia casi total de luz tuvo consecuencias catastróficas, siendo los primeros en extinguirse y produciendo una desaparición que, aunque masiva, fue gradual. Con todo, la dinastía de los dinosaurios llegaba a su fin.

En esta lógica, el Tiranosaurio Rex pareciera ser uno de los supervivientes a la catástrofe biológica dado que, al menos en términos semióticos, permanece aún como uno de los dinosaurios más recurrente en los textos de la cultura. Según afirma Joaquín Moratalla (2008), el Tyrannosaurus rex ("rey lagarto tirano") parece ser uno de los principales cazadores activos que, a veces también carroñero y oportunista, comporta una de las biodinámicas más sorprendentes del mundo prehistórico. De extrema agresividad, con un cuerpo de cinco metros de largo y dos de alto, y dientes de treinta centímetros, el Rex se posiciona como uno de los mayores depredadores del Cretácico: el "último gran superdepredador" (Moratalla, 2008: 72). Aunque esqueletos completos no hayan sido encontrados hasta finales de la década de los '80, no resulta imposible imaginarnos la sorpresa y la incertidumbre que debe haber generado el descubrimiento del primer resto fósil de un cráneo de esta especie a mediados del siglo XX. Desde entonces, la ciencia se esmera por llenar los vacíos etológicos y morfológicos del Rex, y el arte, por su parte, pareciera dedicarse a lo mismo con su propio afán.

Ahora bien, a partir de esta cuestión, creemos que resulta posible hipotetizar que la cultura construye el cuadro de mundo presemiótico a partir de un mecanismo de traducción que busca, como dijera Lotman, cubrir cierta "mancha de sentido" (1996 [1992]: 32). Como ya observáramos, la teoría lotmaniana nos lleva a entender que la cultura (con todos sus órdenes, discursos y textos) se configura como una estructura que procesa la información que proviene del exterior (el mundo natural, el mundo precultural) para expulsarla creativamente: allí donde resulta imposible traducir sentidos, los textos trabajan de manera creativa para ocupar los 
vacíos semióticos. En otras palabras, entender cómo los sistemas culturales procesan fenómenos del mundo biológico como la existencia de especies prehistóricas es indagar sobre las diferentes traducciones y trasposiciones que los textos comportan y que buscan siempre fundamentar la existencia humana sobre la base de lo animal, sean estas especies in praesentia o in absentia. En esta lógica, los textos que pertenecen a la esfera artística poseen un lugar especial por ser aquellos que comportan el mayor caudal de información e integran creativa y dinámicamente las restantes organizaciones discursivas, tales como la científica.

Para dar cuenta de ello, abordaremos de manera exploratoria un recorrido de textos contemporáneos que nos permiten repensar el lugar actual del Tiranosaurio. En estos casos, las trasposiciones estéticas de este dinosaurio abren una serie de interrogantes en torno a su figura: ¿qué pasa cuando la razón de la (hipotética) agresividad del Tiranosaurio desaparece? ¿Qué hubiera sucedido si el ser humano hubiera podido convivir con ellos? ¿Cómo se trabaja de manera creativa una morfología y un comportamiento del que poco sabemos o del que, al menos, tenemos hipótesis verificables y refutables? Con el objeto de arrojar luz a estos cuestionamientos (o, al menos, de producir otros nuevos), observaremos tres modelos actuales y, al mismo tiempo, diferentes para el tratamiento de este cuadro de mundo que ubican al Rex como sujeto agresivo, cooperativo y replicativo.

\subsection{Modelo 1. Un dinosaurio agresivo}

Primer caso: secuela del clásico cinematográfico iniciado en 1993, Jurassic Park, y bajo la dirección de Collin Tevorrow y la producción de Steven Spielberg, Jurassic World (2015) retoma el mundo narrativo de la franquicia que nos ubica en un centro de entretenimiento zoológico en una isla ficticia cercana a Costa Rica y cuya principal atracción son dinosaurios reconstruidos genéticamente. En esta oportunidad, la historia se relata veinte años después de que abriera por primera vez este parque temático, inauguración siempre fallida dado que las especies no pueden ser controladas y, en plena contemporaneidad, se gesta un caos prehistórico. En este sentido, el filme de Tevorrow replica el fracaso del parque jurásico, incorporando algunos elementos que merecen ser atendidos.

El reciente texto centra su trama en la historia de Claire Dearing (Bryce Dallas Howard), directora del centro, quien, por pedido del dueño, llevará 
un proyecto biotecnológico cuyo objetivo es desarrollar nuevas especies de dinosaurios ya que, como refiere la protagonista, "no one is impressed with dinosaurs anymore (...) Consumers want them bigger, louder, with more teeth" (Tevorrow, 2015). En este proceso, el principal ejemplar será una hembra modificada del clásico Tiranosaurio: la Indominus rex ("rex indomable"). Combinación morfológica de otras especies jurásicas, esta Rex posee mayor inteligencia (reacciona de manera creativa, su memoria es más aguda), nuevas herramientas biológicas (es capaz de reconocer registros térmicos y camuflarse) y una agresividad incontrolable (aunque se crían dos ejemplares, esta es la única superviviente luego de haberse comido a su gemela en un rapto de ira). La trama de la película tomará otro cariz cuando este experimento se escapa y Claire se ve obligada a recurrir a Owen Grady (Chris Pratt), un ex-marine devenido investigador del comportamiento de los dinosaurios que trabaja en el parque entrenando a especímenes de velocirráptor. Desatado el caos en un parque repleto de visitantes y en la búsqueda de este ejemplar que destroza todo a su paso, los protagonistas terminarán por entender que la Indominus "is learning where she fits on the food chain" (Tevorrow, 2015).

Ahora bien, podemos observar que se estructuran dos series de tensiones ideológicas en torno a la modelización del tiranosaurio que, tanto a nivel morfológico como comportamental, ofrecen una crítica al lugar de lo humano en un cuadro de mundo que, aunque prehistórico en la actualidad, se rige por las reglas de la esfera ecológica o aquello que Lotman (1999) definió como el "confín fisiológico". En primer lugar, destacamos que, gracias a los descubrimientos recientes de la genética, estos investigadores desarrollaron aquello que definen como "a whole new frontier" (Tevorrow, 2015): híbridos modificados genéticamente. El genetista a cargo de la creación de estos seres, el Dr. Henry Wu (BD Wong), explicará que estos no son gestados, sino "designed" (Tevorrow 2015). Nos referimos a un trabajo de ingeniería, una modelización genética de la vida prehistórica, a partir de la cual el ser humano juega con la creación de vida (mitema frankenstaniano que la ciencia ficción repite asiduamente). En una conversación con el dueño del parque, el genetista recordará que

Nothing in Jurassic World is natural. We have always filled gaps in the genome with the DNA of other animals. And if the genetic code was pure, they will look quite different. But you never asked 
for reality. You only asked for more teeth (Tevorrow, 2015).

En este punto, la lectura del film parece instaurar el interrogante en torno al modo de modelización de los dinosaurios: ¿estamos ante una reconstrucción verosímil que tiene fundamentación científica? ¿O ante un imaginario cultural que este centro jurásico, atravesado por las leyes de mercado, se ve obligado a replicar? ¿Cómo la Rex rellena aquí el abismo de sentidos en torno a la imaginería presemiótica? Cabe recordar que, a nivel visual (podríamos decir morfológico), la especie es el resultado de un proceso de "des-extinción", plausible gracias a la constitución del $\mathrm{ADN}$, abriendo interrogantes sobre los aspectos éticos que conlleva la manipulación genética.

En segundo lugar, en Jurassic World, el intervalo semiótico ofrece un mecanismo para repensar la etología de las especies, particularmente aquella que apunta a una matriz de agresividad como vector común en todo ser vivo, sea este contemporáneo o atávico. En este sentido, se ponen de manifiesto dos miradas encontradas. Mientras para los ingenieros genéticos la manipulación del genoma jurásico es un testeo de la posición, nuestra especie dentro la cadena trófica en el mundo natural (dirá el dueño que "Jurassic World exists to remind us how very small we are, how new", Tevorrow, 2015), los militares, de manera análoga, encuentran en el dinosaurio una máquina de guerra en potencia. A diferencia de un espía que puede alternar posiciones o de un droide que puede ser hackeado, las especies prehistóricas son instintos manipulables: "they've got millions of years of instincts in their cells, instincts that we can program. Their loyalty cannot be brought" (Tevorrow, 2015). Como pudimos observar en investigaciones anteriores (Gómez Ponce, 2016), el instinto deviene aquí categoría semiológica: a través de estrategias discursivas (y de la traducción de premisas de las ciencias naturales que se vuelven funcionales para armar el argumento de la película), el instinto "pierde" su trazo biológico y deviene herramienta por medio de una excitación, una manipulación (diseñable) mediante ingeniería genética.

En ambos casos, la agresividad instintiva del dinosaurio da cuenta de que la lucha ("the struggle") es parte de la naturaleza: la supervivencia del más fuerte depende de la posición del ser vivo en la pirámide de la vida y de las ventajas que este puede sacar para escalonarse en la cadena. No obstante, una perspectiva opuesta la ofrece Owen, esta suerte de 
líder de la manada jurásico que lleva años estudiando y entrenando a lo velocirraptores, la especie enemiga por antonomasia en las secuencias anteriores de la franquicia. Este giro resulta interesante dado que, en esta versión, no solo pareciera posible la convivencia con la especie raptora, sino que, además, existe una forma precaria de cooperación con el humano. El etólogo de la prehistoria ha logrado "a bond between man and beasts", porque, después de todo, los dinosaurios "are actually animals" (Tevorrow, 2015).

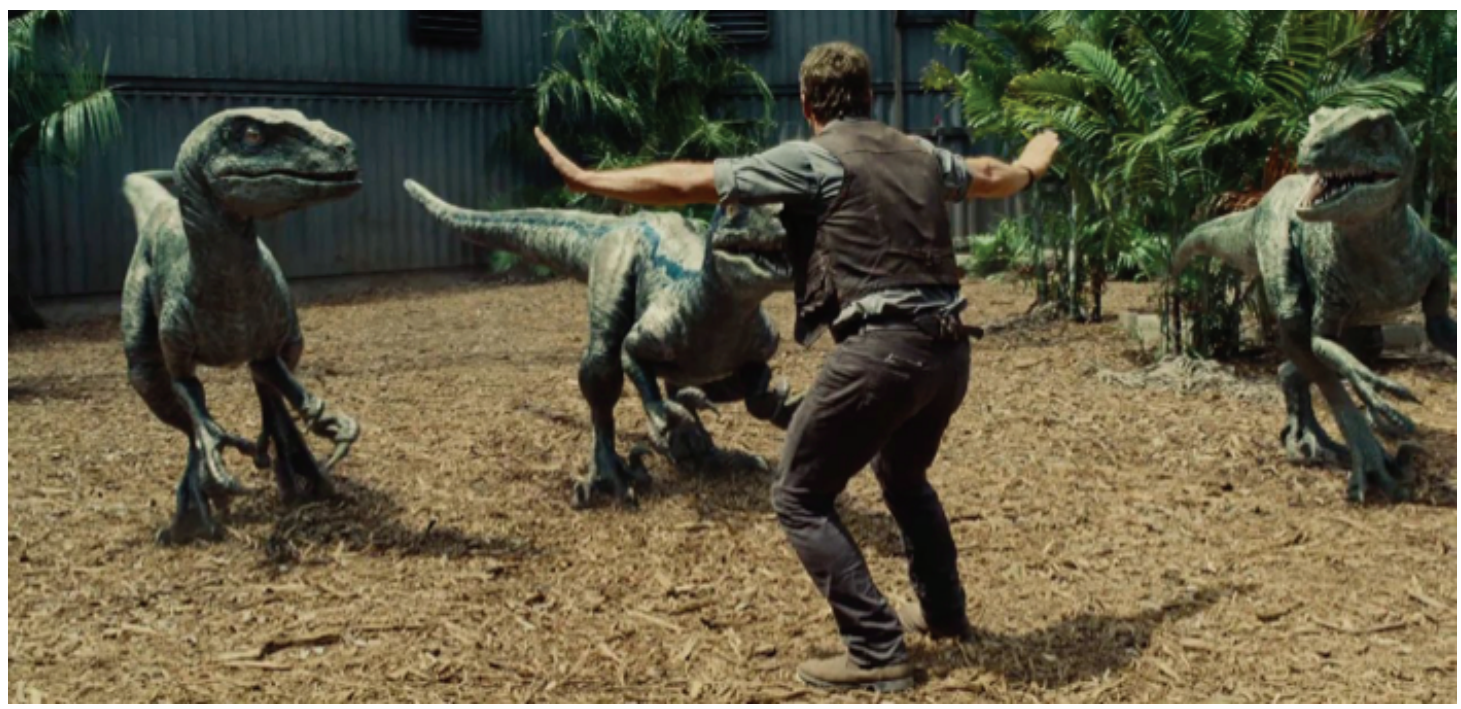

Figura 1

Imagen promocional de Jurassic World (2015). (cinta cinematográfica). Collin Tevorrow (Director), Rick Jaffa (Escritor), Frank Marshal (Productor). Estados Unidos: Amblin Entertainment / Universal Pictures

Para Owen, la hembra Rex no posee el mecanismo principal para canalizar la agresividad: la interacción social. Como bien practica con las manadas de raptores, el etólogo entiende que debe construirse un "mutually respect" en las especies saurias, ya que la influencia recíproca (la convivencia, la experiencia compartida entre los especímenes) es un vínculo esencial. El personaje establece una suerte de cooperación que le permite formar parte del colectivo velocirraptor (él se define como alfa y el espécimen siguiente al mando, Blue, como beta), reviviendo una larga 
discusión entre los dos modelos ideológicos que comporta el discurso biológico (Thompson, 2009 [1987]): el de la agresividad y el del altruismo. Para el filme, en esta lógica semiótica, la única posibilidad de desenlace es enfrentar a esta especie modificada a su proximidad biológica: el original Tiranosaurio. Una vez vencida la hembra, el parque queda deshabitado de humanos, pero ahora las especies jurásicas tienen el terreno libre para impartir sus reinados.

De este modo, en este cuadro de mundo, el caso de la Rex pone de manifiesto un interrogante en torno a "algo instintivo" que ejerce una (im)posibilidad de convivencia con nuestra especie y, por ende, de toda domesticación posible. Como bien refería el filme de 1993 (motivo que se mantiene en las cuatro ediciones), el ser humano "can't just suppress 65 million years of gut instinct" (Spielberg, 1993). Finalmente, a través de esta configuración del Tiranosaurio, no solo triunfa lo instintivo sino, principalmente, lo atávico y prehistórico, refutando así la premisa del plan militar de utilizar los dinosaurios como armas.

\subsection{Modelo 2. Un dinosaurio cooperativo}

The Good Dinosaur (2015, conocida en español como Un gran dinosaurio) es una película animada de la productora Pixar (Disney Pictures), bajo la dirección de Peter Sohn y con un gran elenco de actores que les otorgan voces a los personajes. En este filme dirigido al público infantil, nos hallamos ante un desenlace alternativo a la extinción de los dinosaurios hace 65 millones de años. ¿Qué hubiera pasado si aquel asteroide que colisionó con la Tierra hubiera esquivado su trayectoria y, por ende, las especies jurásicas hubieran seguido su curso evolutivo? El filme responde a este interrogante de una manera creativa, dado que las especies saurias (gracias a la carencia de una presión evolutiva) incursionan en formas de lo que podríamos llamar una cultura: forman núcleos familiares, realizan prácticas ganaderas y agricultoras (sistemas de riegos y plantaciones), $\mathrm{y}$, aun más extraordinario, la facultad de lenguaje reflexivo. En esta relectura ficcional del pasado, nos encontramos con el protagonista de la historia: Arlo, un miedoso Apatosaurio (especie característica del norte de América a finales del periodo Jurásico) que vive con su familia agricultora en una granja en una colina. Su padre, en un intento de que el pequeño perdiera el miedo, es llevado por la corriente de un río y muere, dejando a su familia 
con la carga de la granja (recurso dramático al que, como bien sabemos, Disney recurre asiduamente). El pequeño dinosaurio se pierde y queda desamparado en un territorio que es totalmente desconocido para él.

Con todo, lo interesante en este texto es que Arlo emprende una odisea por el mundo jurásico en la búsqueda por regresar a su hogar, acompañado de un personaje bastante particular: un niño humano que no sabe hablar (apenas gesticula y gruñe) y que se presenta a la manera de un cachorro salvaje que se aventura con el protagonista como una mascota de compañía $\mathrm{y}$, al mismo tiempo, ayudante (le brinda comida, protección y guía) y amigo $^{2}$. En este camino heroico, ambos personajes, Arlo y la cría humana (que el primero nombra como Spot), se toparán con un variado número de dinosaurios que complejizarán la trama y serán tanto colaboraciones como obstáculos en el camino de regreso de nuestro protagonista.

Así, Arlo y Spot se encontrarán con tres Tiranosaurios rancheros de acento sureño que, en clara parodia a los cowboys del oeste norteamericano, buscan a su rebaño: Nash (A.J. Buckley), Ramsey (Anna Paquin) y su padre, Butch (Sam Elliot). Estos Rexs ganaderos son seres sociales, alejados de toda práctica agresiva y comportan sus propias manifestaciones artísticas, tales como tocar la armónica y contar historias pasadas alrededor del fuego (descubrimiento que, según podemos observar, los dinosaurios han alcanzado en este cuadro de mundo). El pequeño dinosaurio y su acompañante humano colaborarán con los Rexs, al mismo tiempo que aprenden una lección de vida importante para nuestro protagonista. Porque, una vez resuelto el misterio del hurto del rebaño, Butch, el patriarca de esta manada prehistórica, reflexionará sobre el miedo como condición necesaria para todas las especies, al explicar cómo obtuvo las cicatrices que orgullosamente muestra. Al recordar su encuentro con un cocodrilo, le dirá a Arlo que

If you don't get scared of a croc biting you on the face, you ain't alive. Listen, kid, you can't rid of fear. It's like Mother Nature: you can't beat her or outrun her, but you can get through it. You can find out what you're made of (Sohn, 2015).

2. Además de estos dinosaurios que hablan y cultivan, el texto ficcional opera aquí a través de otro "error histórico" dado que, como bien mencionáramos líneas arriba, el surgimiento de los primates (y, por ende, del Homo sapiens), solo fue posible gracias a la desaparición de las grandes especies. En términos paleobiológicos, la convivencia entre ambos seres vivos hubiera sido, en principio, imposible. 
En estos personajes, el miedo, aquella emoción que Lotman (1970) hipotetizó como una de las principales regulaciones de los sistemas culturales, junto con el honor y la vergüenza, se construye como parte esencial en la vida dentro del mundo natural. Pese a su gran tamaño y a ser los depredadores por excelencia en la prehistoria (o, en este caso, los ganaderos), los Tiranosaurios comprenden que temer es un sentimiento necesario, al que deben enfrentarse con el objeto de conocerse a sí mismos. Arlo entiende que esta lógica es visible en su amigo humano, quien, pese a ser un "cachorro", ha atravesado un sinnúmero de peligros y le ha ayudado a sobrevivir en este mundo hostil. Aprendida la lección, los protagonistas siguen su camino y, luego de variadas proezas, llegan a aquel lugar que llaman "hogar".

Pese a la amistad construida y al gran número de amigos encontrados, Arlo y Spot son dos especies diferentes que, aunque pudieron establecer un diálogo precario (entre aullidos y gestos), pertenecen a esferas distantes: un lenguaje rudimentario que organiza una frontera no como límite infranqueable, sino como zona altamente porosa y dialógica. Es por este motivo que, al llegar a la colina, Spot será adoptado por lo que pareciera ser una familia de humanos más evolucionados, quienes vienen siguiendo su rastro. El cachorro humano, huérfano pero lo suficientemente fuerte para sobrevivir por sí solo, necesita del mismo vínculo afectivo que Arlo: ambas especies, requieren de ese círculo social cercano que llaman familia.

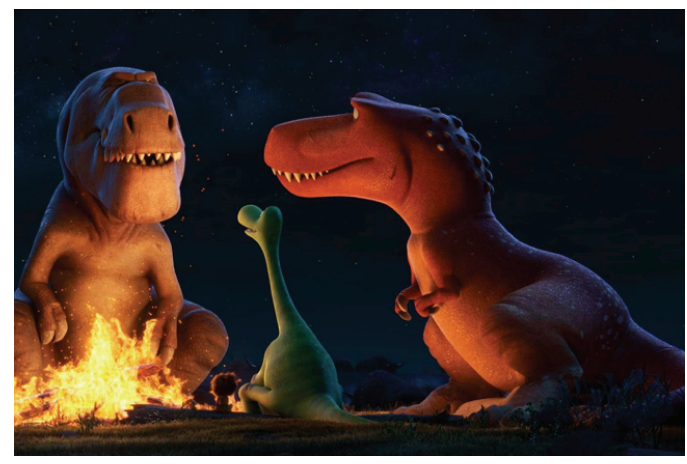

Figura 2

Arlo, Spot y los Tiranosaurios, relatando historias junto al fuego. Imagen promocional. The Good Dinosaur (2015). (cinta cinematográfica). Peter Sohn (Director), Erick Benson (Escritor), Denise Ream (Productora). Estados Unidos: Pixar Animation Pictures / Walt Disney Pictures. 
Con todo, el cuadro de mundo que constituye este filme da cuenta de una alternancia de roles que no está marcada por la diferencia biológica, sino por prácticas culturales, dado que la cultura es poseída por los dinosaurios y los humanos, por su parte, se encuentran en estado salvaje (o, al menos, en vía de desarrollo cultural). Existen, en este aspecto, dos factores fundamentales a considerar: que, en primer lugar, los dinosaurios son capaces de expresarse mediante formas complejas de lenguaje (no solo hablan, sino que, además, dejan sus marcas como una suerte de firma y poseen nombres propios) y que, en segundo lugar, el estado salvaje se encuentra en el pequeño humano. En este último aspecto, como bien refería Lotman (1999), radica una de las distancias fundamentales con el mundo animal: parecería que, en principio, el ser humano es la única especie capaz de individualizar a sus pares. En la teoría lotmaniana, el nombre propio se instaura como "la más aguda manifestación de la naturaleza humana" (1999: 52).

En este sentido, resulta de importancia la capacidad cultural "impredecible" que el pequeño humano manifiesta, poseedor de ciertos "trucos" que les permiten a ambos personajes sobrevivir: comporta ciertos ases de inteligencia que se enfrentan a las inclemencias del entorno hostil y desconocido para ambos. Arlo pensará que su compañero es una "crazy creature", aunque los restantes dinosaurios, incluidos los Tiranosaurios, se encargarán de demostrar que "clearly you have a connection" (Sohn, 2015). Con todo, entre el Apatosaurio, los Rexs y el propio humano la convivencia ha sido posible: sobre la base de la empatía y la cooperación, las especies (aquellas prehistóricas, aquellas en vías de desarrollo evolutivo) confluyen en un mismo espacio dialógico que organiza al cuadro de mundo prehistórico como cartografía altruista y colaborativa.

Cabe destacar además la importancia que adquieren los valores y las prácticas socioculturales que esta película traduce en una narración para niños mediante figuras del universo jurásico como recursos retóricos. En tal sentido, en este filme el dinosaurio no solo "funciona" como modelización de una especie jurásica, sino que además deviene figura representativa del ser humano para hablar de la necesidad humana de desarrollar prácticas cooperativas: se trata, a fin de cuentas, de un mensaje de índole moral que el texto incorpora a través de este cuadro de mundo presemiótico que perseguimos en el presente trabajo. 


\subsection{Modelo 3. Un dinosaurio replicado}

Finalmente, el tercer caso que revisaremos atañe al mundo digital. Más específicamente, nos referimos a uno de los fenómenos recientes que se propagan diariamente por las redes sociales: los memes. Combinación de parodia y estilización, parecería que los memes se presentan como uno de los productos más intertextuales en la contemporaneidad. Realizados con programas de edición de imágenes (desde los más complejos hasta aquellos más básicos), con poca definición y a veces fragmentos de frases, los memes trabajan creativamente imágenes de películas, libros, series o simplemente crean sus propios personajes y escenarios que se cristalizan en futuros usos. El nombre es deudor de la propuesta de Richard Dawkins (1986) sobre el modo de funcionamiento de los registros culturales: de la misma forma que el ADN es un replicante constante de una información biológica, la cultura se constituye a través de productos meméticos, es decir, memes.

Como bien señala Silvia Barei (2012), nos hallamos ante un lenguaje cultural relativamente reciente que requiere otro tipo de competencias cognitivas en una construcción del mundo ligada a herramientas digitales: aquello que se entiende como "modelización digital". En este sentido, todo meme pone de manifiesto una mímesis que "se licua en la semiosis y la modelización virtual aporta a la modelización estética (¿original?) un nuevo régimen de visibilidad, un cambio fundamental en las coordenadas espacio temporales y en la sobreimpresión de textos metonímicos" (Barei, 2012: 408). Con todo, resulta casi imposible encontrar el preciso momento en que surge determinada imagen y, más difícil aun, quién es su emisor originario: nos referimos a una autoría que parece perderse en la inconmensurable cantidad de representaciones que organizan un continuum de acercamientos y divergencias a lo largo de la red. Una vez modificada la imagen original, el producto circula libremente sin regímenes legales que parecieran cubrirlos y sufriendo modificaciones recursivas a partir del uso que cada lector pretenda darle. Modelo peirceano de la era digital, la semiosis aquí también es infinita: los memes no poseen principio ni final, pero configuran un propio cuadro de mundo en otro tipo de soportes culturales.

En esta lógica, que recupera activamente registros de memoria 
de todos los soportes y las culturas, el dinosaurio encuentra un "nicho semiótico" especial, como elemento recurrente para ironizar ciertos aspectos de la cultura contemporánea. Desde los que parodian grandes filmes hasta aquellos que se encargan de trazar nuevamente la distancia entre evolucionismo y creacionismo, los memes en torno a las modelizaciones de los dinosaurios son innumerables. No obstante, en este trabajo, nos interesa un modelo particular que proponen estas textualidades recientes. Nos referimos a la hilarante replicación de memes del Tiranosaurio que concentran su sentido paródico en uno de los rasgos más sobresalientes de esta especie: el largo de sus brazos. Aunque los científicos hayan explicitado que la capacidad predatoria de este dinosaurio recae en su cráneo, su gran dentición y la fuerza de su mandíbula (Moratalla, 2008), la cultura aún se sigue preguntando cómo tamaño espécimen pudo sobrevivir con extremidades tan cortas. Los ejemplos son innumerables y un breve rastreo por la web obtiene como resultado las más variadas reproducciones. Veamos algunos ejemplos:
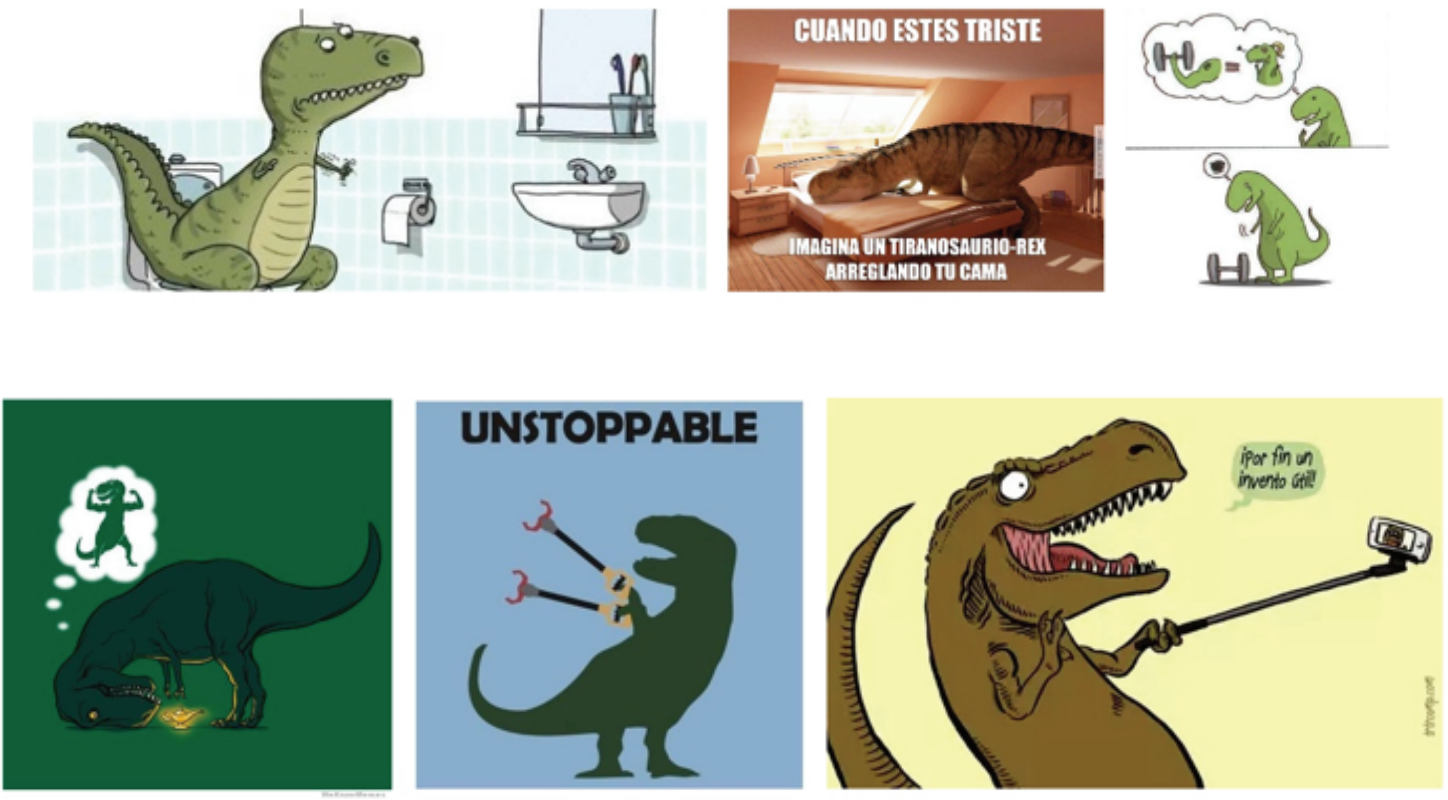

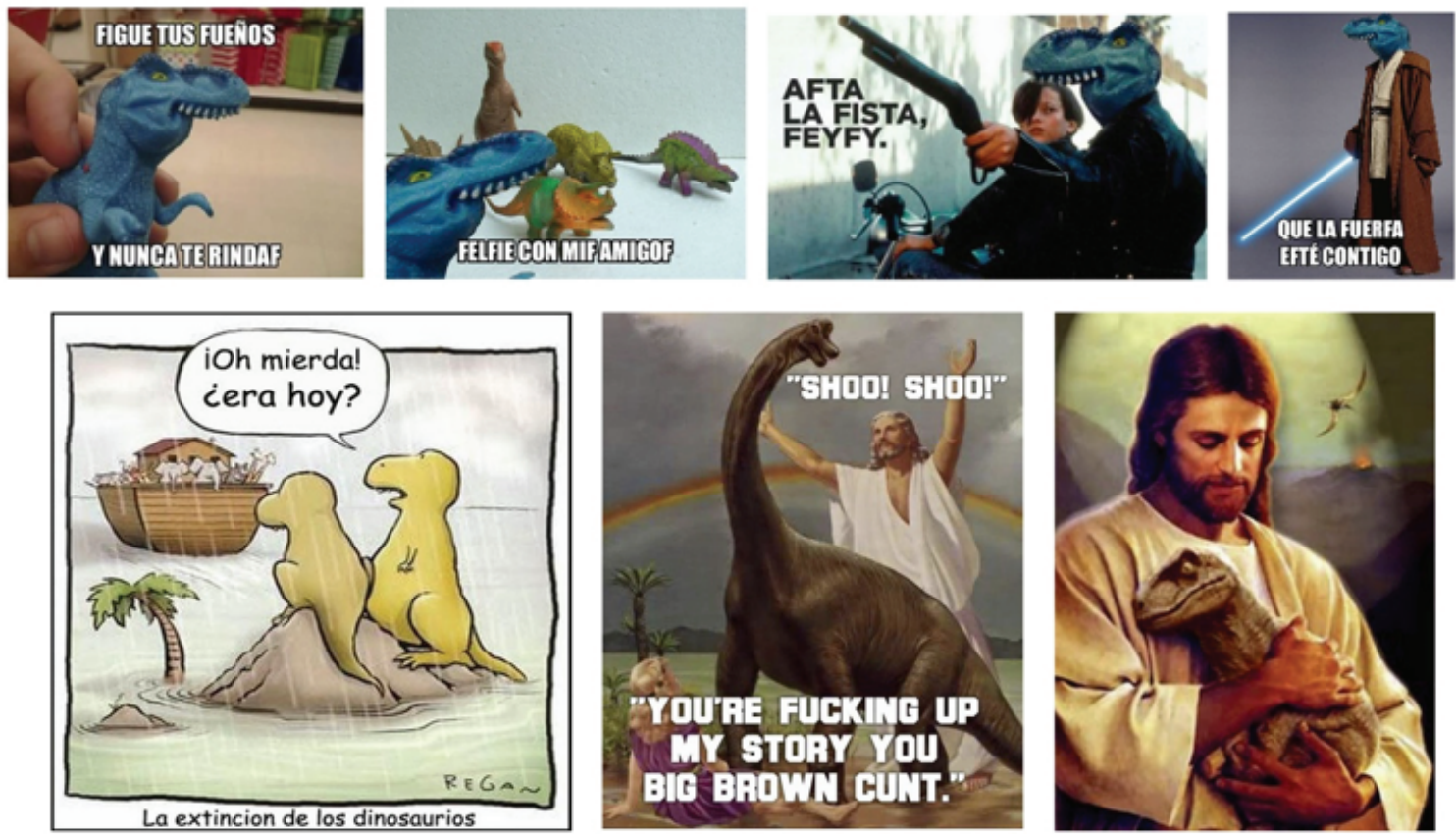

Figura 3. Memes de los dinosaurios

En una primera serie de imágenes, atendemos a las imposibilidades prácticas que tendría el Tiranosaurio al querer, por ejemplo, alcanzar el rollo de papel higiénico, tender una cama, levantar una pesa, o frotar lo que pareciera ser la lámpara mágica de Aladino. En otros casos, los memes resuelven de manera ingeniosa esta limitación morfológica del saurio: una suerte de manos mecánicas y uno de los inventos más controvertido de los últimos tiempos, el selfie stick, desplazan esta problemática corporal.

No obstante, uno de los casos recientes más controvertidos ha sido el meme generado a partir de una fotografía de un juguete de Tiranosaurio que se mastica su propia mandíbula. Como si el dinosaurio tuviese alguna dificultad para la producción del habla por este "defecto" morfológico, los creativos autores anónimos han construido innumerables imágenes en las cuales todo sonido consonántico puede ser reemplazo por una " $F$ ". En primer lugar y bajo el inspirador lema "figue tuf fueñof y nunca te rindaf", el Rex de plástico se convirtió en un recurrente continuum que desplegó los más variopintos intertextos que lo llevaron a protagonizar paródicamente filmes como Terminator, Star Wars o simplemente, ser parte de una selfie con otros dinosaurios de juguete. 
En todos los casos, estos memes, textos culturales díscolos, están orientados a recrear, a través del humor, una especie de la que poco sabemos, pero aún sigue sorprendiéndonos. Si con Jurassic World el Tiranosaurio se postulaba como una competencia biológica para el hombre y, por otro lado, en The Good Dinosaur funcionaba como elemento cooperativo, en estas textualidades le permiten a la cultura dar cuenta de ciertas "limitaciones" del mundo natural que son, a fin de cuentas, también propias de lo humano. Estos memes cuestionan la idea de un diseñador perfecto de la naturaleza: de aquello que Richard Dawkins (2002[1976]) denominó un "relojero ciego". En este cuadro de mundo, las especies saurias se vuelven funcionales para dar cuenta de que esta larga discusión biológica donde la naturaleza operaría de maneras misteriosas y que en la evolución hay un condimento azaroso que aún la ciencia no puede explicitar.

Asimismo, puede destacarse el hecho de que, en los memes, los dinosaurios son recursos semióticos que permiten hablar del orden de lo humano (Barei, 2013), aspecto similar a lo que ocurre con la película de Disney pero, en este caso, aplicado en clave paródica. El humor y la parodia se presentan, en tal sentido, como puentes que permiten la traducción entre mundo cultural y mundo prehistórico, inscribiéndose en coordenadas contemporáneas. En tal sentido, se recupera el papel capital que ocupan los animales y la imposibilidad, según comentáramos con Lotman, de separarlos del colectivo humano: son, finalmente, un "paradigma inevitable" que aun en la actualidad explica nuestra condición con los más variados matices de sentido.

\section{BREVES CONCLUSIONES}

De manera exploratoria, hemos podido observar cómo a través de diversas textualidades, tanto mundo natural como mundo prehistórico ingresan en el orden cultural mediante los lenguajes que habilitan su traducción. Cuanto más "alejado" estén los sentidos del campo de la esfera humana (ya sea en el tiempo o en la distancia espacial), mayor es el empeño que manifiesta el sistema por insertarlos en su interior (Lotman, 1999). En este punto, ocupan un lugar privilegiado los textos artísticos como mecanismos que ponen de manifiesto un modo cognoscitivo de pensar el lugar de lo humano en relación con especies que pueden o no haber estado 
presentes en su historia evolutiva: nos referimos a textos (filmes, memes) que, desde la semiótica de la cultural, son configuraciones semánticas que cartografían un cuadro de mundo a través de "algo arcaico" (Lotman, 1999, 45). Son textos que permiten reconocer toda una mitología del principio en esto que hemos llamado el cuadro de mundo presemiótico.

El campo teórico de la semiótica de la cultura de Iuri Lotman y algunas categorías dispersas por su edificio teórico nos permitieron indagar sobre modos contemporáneos de traducción de un pasado no vivido, centrándonos en la categoría poco explorada del cuadro de mundo, indagando sobre un cuadro de mundo anclado en una presemioticidad o un sentido anterior al sentido. Desde esta perspectiva, el mundo cultural y el mundo de la vida (como así también presente y pasado) no parecerían estar tan alejados. Porque, si ante los ojos de la cultura, la naturaleza se opone a los fenómenos sociales y culturales, la semiótica de Lotman permite demostrar que existen lenguajes que generan un "quiebre" con el orden biológico y dan cuenta, en palabras del semiólogo, de la "decadencia fisiológica". Todo fenómeno o acontecimiento biológico tiene que volverse "humano" para influir en la conciencia del hombre, y esto solo es posible a través de la adquisición de una "inteligibilidad semiótica" (1999: 183, la cursiva es nuestra). En esta oportunidad, un quiebre de sentidos que ubica al dinosaurio en una nueva frontera.

\section{REFERENCIAS BILIOGRÁFICAS}

BAREI, S. (2012). "Efectos retóricos de modelización: perspectivas desde la complejidad cultural". En Actas del I Congreso Internacional de Retórica e Interdisciplina, Alejandra Vitale (comp.), 399-413. Buenos Aires: Asociación Argentina de Retórica.

(2013). "Fronteras naturales / fronteras culturales. Nuevos problemas / nuevas teorías". En Cultura y formas de la vida I. Perspectivas teóricas, Silvia Barei y Ariel Gómez Ponce (comps.), 13-28. Córdoba: Ferreyra Editor.

y ARÁN, P. (2002). Texto, memoria, cultura. El pensamiento de Iuri Lotman. Córdoba: Ediciones El Espejo.

et al. (2006). El orden de la cultura y las formas de la metáfora. 
Córdoba: Ferreyra Editor.

CURTIR, H. et al. (2008). Biología. Buenos Aires: Médica Panamericana. DAWKINS, R. (1986). The Blind Watchmaker. New York: Penguin.

(2002 [1976]). El gen egoísta. Las bases biológicas de nuestra conducta. Barcelona: Salvat.

GÓMEZ PONCE, A. (2015). "El devenir animal. El depredador como manifestación cultural". En Seminario de Verano I. La pregunta por lo humano, Silvia Barei (ed.), vol. 1, 93-123. Córdoba: Ferreyra Editor. (2016). "La morfogénesis animal. Acerca del depredador y la presa en la complejidad cultural". En Seminario de Verano IV. La pregunta por lo humano. Hombres / Dioses / Monstruos / Robots, Silvia Barei (ed.), 85-109. Córdoba: Ferreyra Editor.

LOTMAN, I. (1970). "Semiótica de los conceptos de 'vergüenza' y 'miedo'”. En Semiótica de la Cultura, Manuel Sánchez Cáceres (comp.), 205-207. Madrid: Cátedra.

(1990). Universe of the Mind. A Semiotic Theory of Culture. Bloomington: Indiana University Press.

(1996 [1992]). "La retórica". En La Semiosfera I, Desiderio Navarro (ed. y trad.), 118-142. Madrid: Frónesis Cátedra.

(1998 [1969]). "Sobre el metalenguaje de las descripciones tipológicas de la cultura". En La Semiosfera II, Desiderio Navarro (ed. y trad.), 93-123. Madrid: Frónesis Cátedra.

(1998 [1986]). "La memoria de la cultura". En La Semiosfera II, Desiderio Navarro (ed. y trad.), 152-162. Madrid: Frónesis Cátedra. (1998 [1993]). "La cultura como sujeto y objeto para sí misma". En La Semiosfera II, Desiderio Navarro (ed. y trad.), 140-151. Madrid: Frónesis Cátedra.

(1999). Cultura y explosión. Lo previsible y lo imprevisible en los procesos de cambio social. Barcelona: Gedisa.

(2000 [1992]). "Sobre la dinámica de la cultura". En La Semiosfera III, Desiderio Navarro (ed. y trad.), 194-214. Madrid: Frónesis Cátedra.

MORATALLA, J. (2008). Dinosaurios. Un paseo entre gigantes. Madrid: Editorial Adaf.

MORIN, E. (2011 [1990]). Introducción al pensamiento complejo. Barcelona: Editorial Gedisa.

SÁNCHEZ, T. (2009). La historia de la vida en pocas palabras. Córdoba: 
Editorial Facultad de Ciencias Exactas y Naturales.

SEBEOK, T. (2001). Signs: an introduction to semiotics. Toronto: University of Toronto Press Incorporated.

SOHN, P. (2015). The Good Dinosaur (cinta cinematográfica). Peter Sohn (Director), Erick Benson (Escritor), Denise Ream (Productora). Estados Unidos: Pixar Animation Pictures / Walt Disney Pictures.

SPIELBERG, S. (1993). Jurassic Park (cinta cinematográfica). Steven Spielberg (Director), Michael Cruchton (Escritor), Kathleen Kennedy (Productor). Estados Unidos: Amblin Entertainment / Universal Pictures.

TEVORROW, C. (2015). Jurassic World (cinta cinematográfica). Collin Tevorrow (Director), Rick Jaffa (Escritor), Frank Marshal (Productor). Estados Unidos: Amblin Entertainment / Universal Pictures.

THOMPSON, W. (2009 [1987]). "Las implicaciones culturales de la nueva biología". En Gaia. Implicaciones de la nueva biología, James Lovelock et al. (comps.), 11-34. Barcelona: Kairós.

TOPOROV, V. (2002). "Animales”. En El árbol del mundo. Diccionario de imágenes, símbolos y términos mitológicos, Rinaldo Acosta (ed.), 23-25. La Habana: Casa de las Américas / Criterios.

Recibido el 5 de abril de 2017.

Aceptado el 28 de abril de 2017. 